\title{
Forest carbon storage along the north-south transect of eastern China: Spatial patterns, allocation, and influencing factors
}

\author{
Ding Wen ${ }^{\mathrm{a}, \mathrm{b}}$, Nianpeng $\mathrm{He}^{\mathrm{a}, *}$ \\ ${ }^{\text {a }}$ Key Laboratory of Ecosystem Network Observation and Modeling, Institute of Geographic Sciences and Natural Resources Research, Chinese Academy of \\ Sciences, Beijing 100101, China \\ ${ }^{\mathrm{b}}$ University of Chinese Academy of Sciences, Beijing 100049, China
}

\section{A R T I C L E I N F O}

\section{Article history:}

Received 17 July 2015

Received in revised form 21 October 2015

Accepted 23 October 2015

Available online 18 November 2015

\section{Keywords:}

Carbon storage

Carbon allocation

NSTEC

Forest

Pattern

Scale

\begin{abstract}
A B S T R A C T
Forests play an important role in sequestrating atmospheric $\mathrm{CO}_{2}$; therefore, understanding the spatial variations and controlling mechanisms of forest carbon (C) storage is important. In this study, we collected data on forest $\mathrm{C}$ storage along a north-south transect of eastern China from literature published between 2004 and 2014. The collected data, which were from over 2000 plots, allowed us to explore the latitudinal patterns in forest $C$ storage. The results showed that vegetation $C$ storage decreased with increasing latitude, while soil $C$ storage increased. This spatial pattern of vegetation $C$ storage was more apparent for mature forests (forest age $>80$ years). Furthermore, latitudinal patterns in forest $C$ storage, both in vegetation and in soil, became stronger with increasing statistical scale, increasing from plot scale to latitudinal scale $\left(2-5^{\circ}\right)$. However, total forest $C$ storage (vegetation + soil) had no apparent latitudinal pattern. Interestingly, the allocation ratios of forest $C$ storage between vegetation and soil had a negative logarithmic relationship with latitude. These results suggest that in eastern China, climatic factors control latitudinal patterns in the forest $\mathrm{C}$ storage of vegetation and soil, albeit in different ways (positive for vegetation and negative for soil), and also control the allocation ratios of forest $C$ storage between vegetation and soil. Furthermore, the latitudinal patterns of forest $C$ storage were opposite for vegetation and soil, resulting from the different climatic controlling mechanism.
\end{abstract}

(C) 2015 Elsevier Ltd. All rights reserved.

\section{Introduction}

Forests, as the main component of terrestrial ecosystems, not only play an important role in the maintenance of regional ecology, but also make a huge contribution to the global carbon (C) balance (Dixon et al., 1994; Warring and Running, 2007; Xu and Jiang, 2015). It is estimated that forests store approximately $45 \%$ of the organic C in terrestrial ecosystems (Bonan, 2008), and their annual $C$ sequestration accounts for two thirds of that in terrestrial ecosystems (Liu et al., 2000). Accurately identifying the spatial patterns and controlling mechanisms of forest $C$ storage is important because enhancing their storage is considered the most effective and economical approach to partially sequestering anthropogenic $\mathrm{CO}_{2}$ emissions (Fang et al., 2007; Gower, 2003; Houghton, 2005). Although some studies have demonstrated that, on a regional scale, vegetation $C$ storage in forests reduces with increasing latitude,

* Corresponding author at: Institute of Geographic Sciences and Natural Resources Research, Chinese Academy of Sciences, Beijing 100101, China. Tel.: +8610 64889263; fax: +861064889399.

E-mail address: henp@igsnrr.ac.cn (N. He). while soil C storage increases (He, 2012; Wang et al., 2001a; Wei et al., 2013; Zhou et al., 2000); most studies have focused on vegetation $C$ storage or soil C storage separately, primarily due to the limitations of data sources. Therefore, the spatial patterns of forest $\mathrm{C}$ storage therefore remain unclear at large scales (Davidson et al., 2000; Kato and Tang, 2008; Liu et al., 2012; Prentice and Fung, 1990). Furthermore, the influences of forest type and statistical scale have not been well addressed, and the spatial patterns and controlling mechanisms of forest $C$ storage (vegetation + soil, the ratio of vegetation to soil) remain unclear (Davidson and Janssens, 2006; Kerr et al., 2003).

Few studies have emphasized the differences in forest $C$ storage at different statistical scales, despite the fact that scale selection is of great importance (Levin, 1992; Luo et al., 2001) and different scales can yield different results (Bakken et al., 2014; Jelinski and Wu, 1996; Wu et al., 2000; Wu and Li, 2006). Miao et al. (2010) demonstrated that the influences of climate factors on forest $C$ storage varied with statistical scale (region, province, and prefecture-level city). Using the data from 363 forest soil profiles of southwest China, they found that the relationships between mean annual precipitation (MAP) and soil organic C(SOC) storage decreased with 
reducing scales. Rastetter et al. (1992) demonstrated that the linear relationships between ecological attributes and SOC storage were stronger at larger scales than at smaller scales. To date, multi-scale methods have not yet been used to explore the spatial patterns and controlling mechanisms of forest $C$ storage at a large scale.

The level of $C$ storage in forest vegetation represents the longterm balance between $C$ absorption (photosynthesis) and $C$ release (respiration and dead biomass). Differently, $\mathrm{C}$ storage in soil represents the net accumulation of new organic matter inputs (e.g., litter, root death, and root secretion) and the decomposition of organic matter (Fan et al., 1998; Fang et al., 1998). Therefore, many factors, including climate, soil properties, and land use, may influence $C$ storage in vegetation and soil by way of different approaches or mechanisms (Herrero and Bravo, 2012; Kato and Tang, 2008; Sollins et al., 1996; Wim, 2014).

It is commonly assumed that climate (e.g., temperature and precipitation) is the key factor controlling the spatial distribution of $\mathrm{C}$ storage (Liu et al., 2014), and previous studies have shown that $C$ storage in vegetation and soil are related to latitude (Wei et al., 2013; Zhou et al., 2000). However it is unknown whether climate control the spatial distribution of $C$ storage in vegetation + soil, or in the ratio of vegetation to soil. Some studies have shown that temperature and precipitation affect the net primary productivity of forests by regulating the supply of energy and water (Couto et al., 2013; Davidson et al., 2000; Prentice and Fung, 1990). For soil, changing temperature represents the dominant driving force for the decomposition of soil organic matter (SOM), while temperature also exerts an auxiliary effect on transpiration and soil water content (Giardina and Ryan, 2000; James, 2001). Therefore, the accumulation of $C$ storage in vegetation and soil mainly depends on temperature and soil moisture at a regional scale (Parton et al., 1993; Van Der Werf et al., 2003).

In order to explore the latitudinal patterns and controlling mechanisms of forest $C$ storage on a large scale, we collected published data (for over 2000 plots) on C storage in vegetation (above ground biomass + root biomass) and soil along the north-south transect of eastern China (NSTEC). NSTEC, the 15th standard terrestrial transect of the International Geosphere-Biosphere Project, is a typical heat-driven latitudinal transect, spanning tropical to cold temperate climates and covering most of forest types in the Northern Hemisphere (Lu et al., 2013; Zhang and Yang, 1995). Therefore, it is an ideal natural laboratory for exploring the spatial patterns and controlling mechanisms of forest $C$ storage on a large scale. The main objectives of this study were to: (1) explore the multi-scale spatial patterns of vegetation and soil C storage in forests; (2) test the assumption that the allocation ratios of $C$ storage between vegetation and soil are controlled by climate at large scale; and (3) reveal the controlling mechanisms on latitudinal patterns of $C$ storage in vegetation and soil.

\section{Materials and methods}

\subsection{Data collection and compilation}

The NSTEC spans a range of climates (cold, temperate, tropical), and includes most of the main forest ecosystems in the Northern Hemisphere (e.g., cold humid forest to temperate forest, subtropical forest, and tropical forest; Sheng et al., 2011; Zhang and Yang, 1995). Mean annual temperature (MAT) ranges from $-3.67^{\circ} \mathrm{C}$ in the north, to $23.15^{\circ} \mathrm{C}$ in the south, and mean annual precipitation (MAP) is from 473.0 to $2265.8 \mathrm{~mm}$.

The data on forest $C$ storage were collected from studies published between 2004 and 2014, including data from over 2000 plots along the $4200 \mathrm{~km}$ transect from northern China to southern China (Fig. 1). In detail, they included the records for 1471 vegetation plots and 1999 soil plots (592 plots for $0-10 \mathrm{~cm}$ soil, 716 plots for $0-20 \mathrm{~cm}$ soil, and 691 plots for $0-100 \mathrm{~cm}$ soil; Fig. 1 and Fig. S1). The plots included approximately $70 \%$ planted forests and $30 \%$ natural forests. Furthermore, there were 72 vegetation plots in cold humid regions, 257 plots in temperate humid and semi-humid regions, 84 plots in temperate arid and semi-arid regions, 226 plots in warm temperate humid and sub-humid regions, 179 plots in north

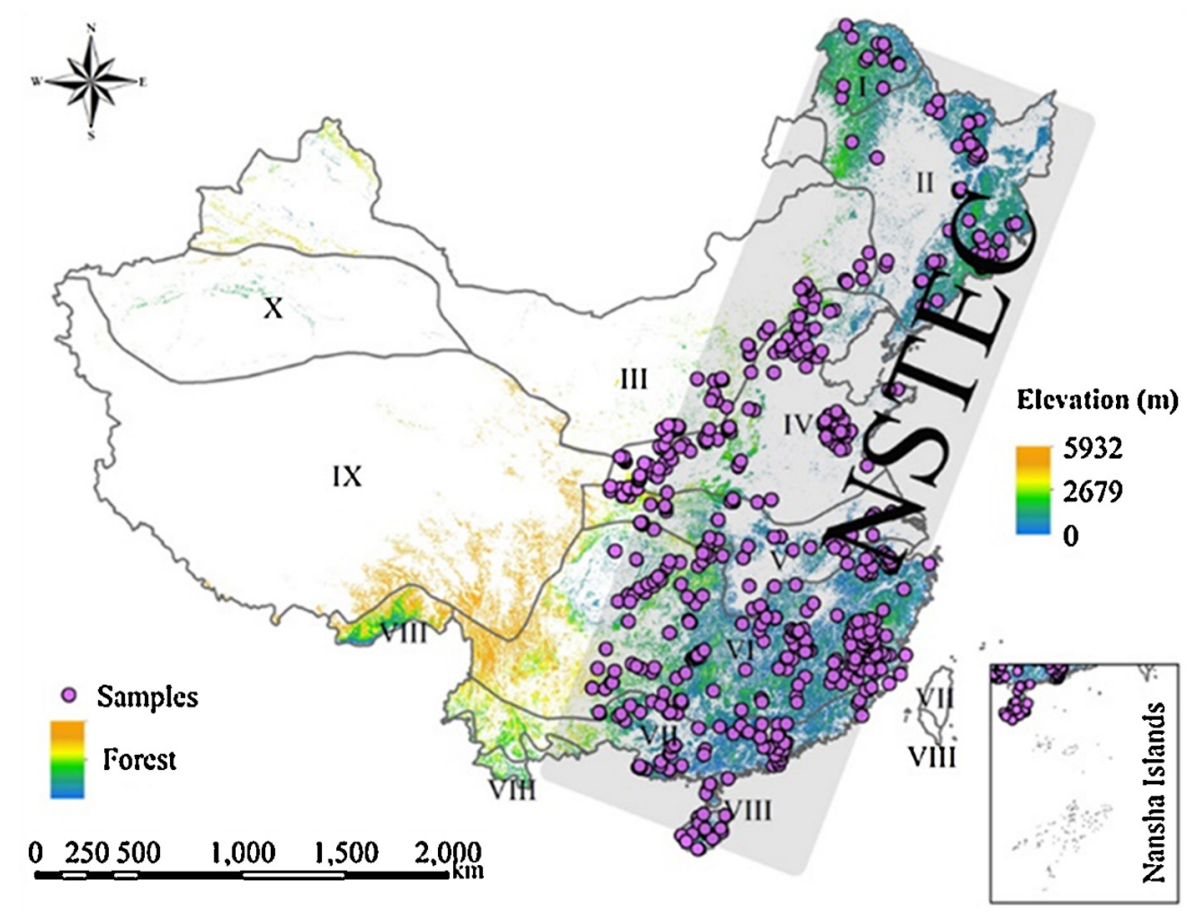

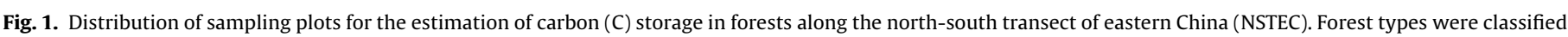

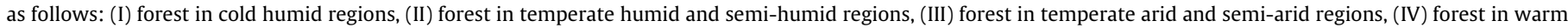

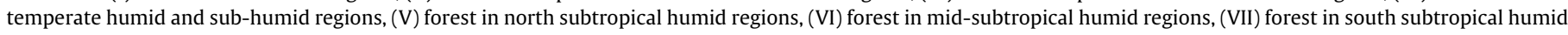
regions, (VIII) forest in tropical humid regions, (IX) forest in Qinghai-Tibet Plateau, and (X) forest in warm temperate regions. 
subtropical humid regions, 428 plots in mid-subtropical humid regions, 162 plots in south subtropical humid regions, and 63 plots in tropical humid regions. For the plots with only forest biomass, a coefficient of 0.5 was used to convert vegetation biomass density to C storage ( $\mathrm{Mg} \mathrm{Cha}^{-1}$; Cook et al., 2014; Yu et al., 2014). Unless the data of SOC storage $\left(\mathrm{MgCha}^{-1}\right)$ were reported in the original studies, they were calculated using Eq. (1):

SOC $=\sum_{i=1}^{n}\left(C_{i} \times B D_{i} \times D_{i} \times S\right)$

where $C_{i}, B D_{i}, D_{\mathrm{i}}$, and $S$ are the SOC content (\%), soil bulk density $\left(\mathrm{g} \mathrm{cm}^{-3}\right)$, soil thickness $(\mathrm{cm})$, and area (ha), respectively.

For records where soil bulk density was not reported, the mean value of the Second Soil Survey in China $\left(1.3 \mathrm{~g} \mathrm{~cm}^{-3}\right)$ was used as a substitute (Wang et al., 2000). For soils sampled at $<100 \mathrm{~cm}$, an empirical relationship was adopted between the SOC content and soil depth in order to fit SOC storage to a $100 \mathrm{~cm}$ soil layer. Empirical relationships were established in our previous studies (Chai et al., 2015; Xu et al., 2015), using long-term monitoring data from 74 typical terrestrial ecosystems in China, with the data sourced from the Chinese Ecosystem Research Network.

MAT $\left({ }^{\circ} \mathrm{C}\right)$ and MAP $(\mathrm{mm})$ were obtained from long-term monitoring data (1961-2010), recorded by 722 meteorological stations in China (Gao et al., 2013). These data were firstly interpolated using kriging methods applied to latitude, longitude, and altitude; we then used the tool "Extract Multi Values to Points" in the ArcMap software to extract corresponding MAT and MAP values for each plot based on its latitude and longitude. The proportions of soil clay (\%), silt (\%), and sand (\%) were obtained from the Second Soil Resource Inventory of China. Forest area for each region was extracted from the China Land Cover Classification System (Liu and Buheaosier, 2000) and the 2008 Chinese land cover data. The Land Cover Classification System, 2008 land cover data, and the contents of soil nitrogen (Soil N, $\mathrm{g} \mathrm{kg}^{-1}$ ), phosphorus (Soil P, \%o), and potassium (Soil K, \%o), were sourced from the China National Science and Technology Platform for Earth System Science Data Sharing (http://www.geodata.cn/).

In order to investigate the differences in $C$ storage among different regions, Chinese forests were divided into ten types corresponding to climate regions (Fu et al., 2001). The NSTEC includes eight forest types (Fig. 1): forest in cold humid regions (I), forest in temperate humid and semi-humid regions (II), forest in temperate arid and semi-arid regions (III), forest in warm temperate humid and sub-humid regions (IV), forest in north subtropical humid regions $(\mathrm{V})$, forest in mid-subtropical humid regions (VI), forest in south subtropical humid regions (VII), and forest in tropical humid regions (VIII).

\subsection{Data analysis}

Prior to statistical analysis, forest $\mathrm{C}$ storage data were divided into two categories (Fig. S2): (1) all forests (where forest age was not considered) and (2) mature forest (forest age $>80$ years). The definition of mature forests followed the criteria of Liu et al. (2014). According to the classical theory of ecology (Odum, 1969), C storage increases rapidly when forests are young and act as strong $C$ sinks. When the forest age is more than 80 years (so called old-growth or mature forests), C storage increases slowly or even tend toward an equilibrium state (Jarvis, 1989; Zhou et al., 2002). Therefore, we defined mature forests as forests with an age $>80$ years (Liu et al., 2014). The differences in the $C$ storage of vegetation and soil among the different climatic regions were tested using one-way analysis of variance with Duncan tests.

Scale selection is fundamental for ecological research (Wiens, 1989); therefore, three statistical scales were chosen to explore the influence of statistical scale on the spatial patterns of forest C storage: (1) plot scale; (2) $2^{\circ}$ latitudinal scale; and (3) $5^{\circ}$ latitudinal scale. Temperature and precipitation, which regularly vary with latitude in the NSTEC (Wang et al., 2015), may result in important latitudinal patterns of forest $C$ storage (vegetation, soil, and vegetation + soil). Therefore, we selected the latitudinal scale to explore the spatial patterns of forest C storage in the NSTEC. At the plot scale, all available data were used in the statistical analyses irrespective of $C$ storage data and other data. Similarly, at the $2^{\circ}$ and $5^{\circ}$ latitudinal scales, we used the mean of data distributed within $2^{\circ}$ or $5^{\circ}$ latitudinal intervals to explore their spatial patterns. For example, the data of $C$ storage within $2^{\circ}$ latitude intervals (e.g., $18^{\circ}-19^{\circ}$, $20^{\circ}-21^{\circ}$, etc.) were arithmetically averaged for $C$ storage in vegetation, soil, vegetation + soil, and for the ratio between vegetation and soil, separately; similarly, the mean of other parameters (MAT, MAP, soil fraction, and soil nutrients) were calculated.

Here, we only used the $2 \circ$ latitudinal scale data to explore the mechanisms controlling the spatial patterns of forest $\mathrm{C}$ storage, because we found that the results at different scales were similar. For vegetation $C$ storage, analyzed factors included climate (MAT and MAP), soil nutrients (SOM, soil N, P, and K), and soil environment (clay, silt, sand content, and $\mathrm{pH}$ ). For soil $\mathrm{C}$ storage, analyzed factors included SOM inputs (vegetation biomass), climate (MAT and MAP) influencing SOM decomposition, and soil properties (sand, silt, clay, soil $\mathrm{N}, \mathrm{P}, \mathrm{K}$, and $\mathrm{pH}$ ) indirectly impacting on SOM decomposition. Structural Equation Modeling (SEM) was used to identify the relative contributions of each factor to $C$ storage in vegetation, soil, and vegetation + soil (Gustafsson and Martenson, 2002). Furthermore, SEM was used to assess the direct and indirect associations of $C$ storage and climate, soil nutrient, and soil environment using the maximum likelihood method in the Amos software (version 17, Chicago, IL, USA). The results were shown as standardized regression coefficients (Barto et al., 2010; Cheng et al., 2014), which can identify the main factors for the spatial pattern of forest $C$ storage. Spatial patterns in the allocation ratios of vegetation to soil $(0-10 \mathrm{~cm}$ soil and $0-100 \mathrm{~cm}$ soil) were investigated at the $2^{\circ}$ latitudinal scale. Path analysis (Petraitis et al., 1996; Sackett et al., 2013) was used to quantitatively investigate the main factors controlling spatial patterns of these allocation ratios. Because some of the predictors are ecologically (and statistically) correlated, we used path analysis to determine significant direct predictors of the allocation ratios, as well as indirect pathways of soil factors. Path analysis is a simple SEM, in which more advanced analyses can incorporate latent, or unmeasured variables (Mitchell, 1992; Petraitis et al., 1996). Our path analysis considered all parameters as three groups: climate, soil texture, and soil nutrients.

Curve fitting methods were used to identify the best functions between the principal factor and forest $C$ storage (vegetation or soil) in mature forests at the $2^{\circ}$ latitudinal scale. The data on vegetation C storage in mature forests published by Luo (1996) were used to validate the models. Due to a lack of corresponding soil data, we used the data of soil $C$ storage in mature forests to construct the models, but used the data of all forests to validate them.

Chinese forest maps were produced using the ArcMap software (version 9.2, ESRI, USA). Other statistical analyses and graphs were conducted using the SPSS software (version 18.0, Chicago, IL, USA) and Origin software (version 8.0, Northampton, MA, USA).

\section{Results}

\subsection{Spatial variations in vegetation and soil $C$ storage in forests along NSTEC}

For all forest plots, vegetation $C$ storage increased significantly from north to south (Fig. 2A). Vegetation C storage was 


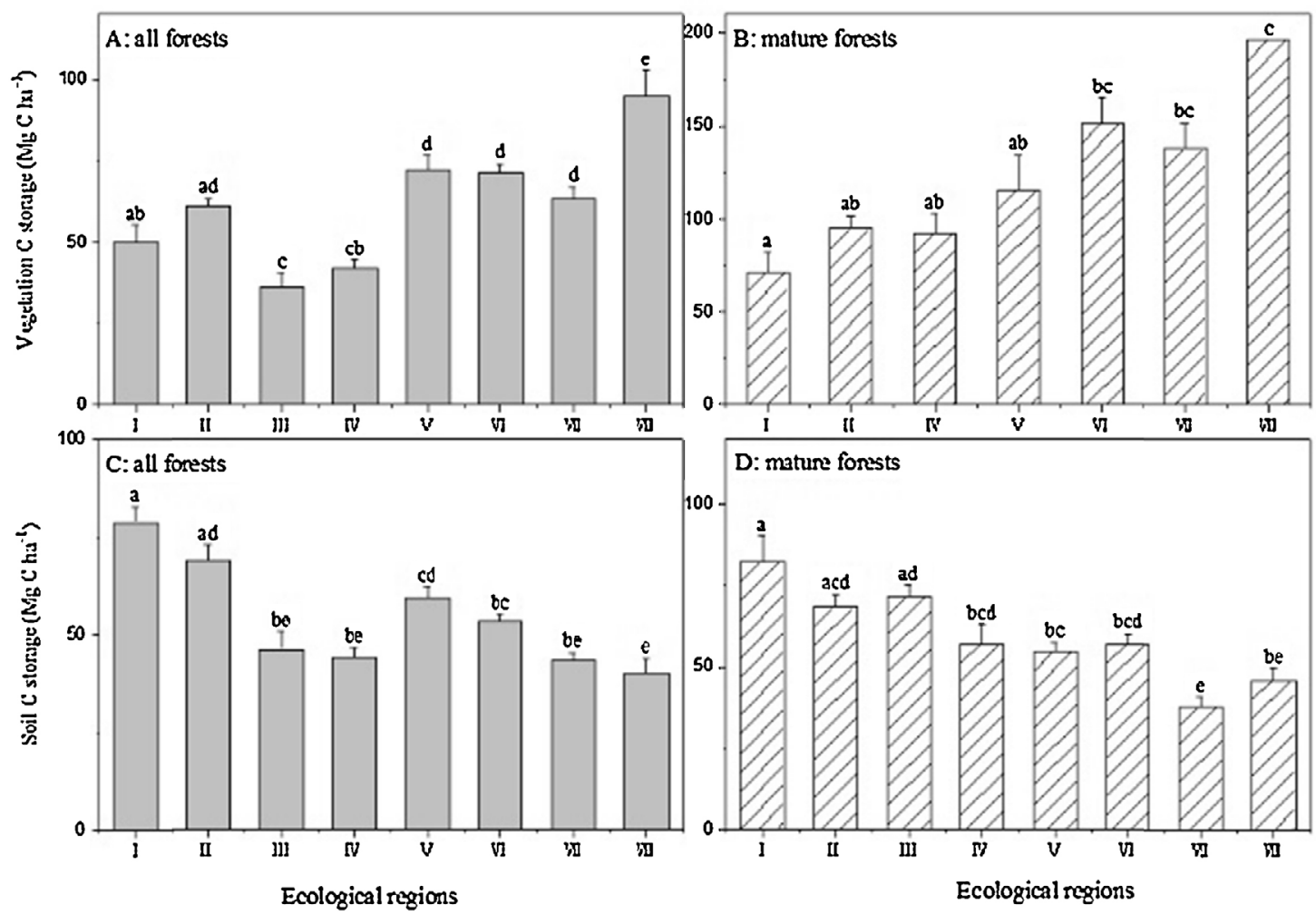

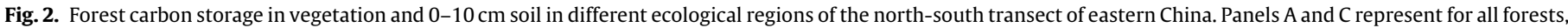

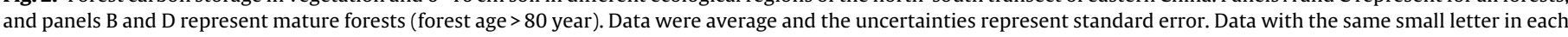
panel indicate no significant difference at the $P=0.05$ level (Duncan test). See Fig. 1 for the abbreviations of forest types.

significantly lower in cold humid regions (I), located to the north, than in the north subtropical humid (V) and tropical humid regions (VIII), located to the south $(P<0.05)$. These differences were stronger when the mature forests alone were considered (Fig. 2B). In contrast, soil C storage in the $0-10 \mathrm{~cm}$ layer showed a clear decrease from north to south, with values significantly different among different regions $(P<0.05$ for all) for both all forests and mature forests (Fig. 2C and D). Similar differences in soil $C$ storage among different climate regions were observed for soil depths of $0-20 \mathrm{~cm}$ and $0-100 \mathrm{~cm}$ (Table S1).

\subsection{Latitudinal patterns in forest $C$ storage at different statistical scales}

At plot scale, vegetation $C$ storage for all forests decreased weakly with increasing latitude (Fig. 3), which was stronger for mature forests. In contrast, soil C storage increased with increasing latitude at all soil depths (Fig. 3; Table S2). For all forests or mature forests, total forest $\mathrm{C}$ storage (vegetation + soil) had no apparently latitudinal pattern (Table S2).

At the $2^{\circ}$ latitudinal scale, vegetation $C$ storage in mature forests decreased exponentially with increasing latitude $\left(R^{2}=0.67\right.$, $P<0.001$; Fig. 3 b), while soil $C$ storage increased exponentially with increasing latitude within the $0-10 \mathrm{~cm}\left(R^{2}=0.60, P=0.001\right)$, $0-20 \mathrm{~cm}\left(R^{2}=0.62, P=0.003\right)$, and $0-100 \mathrm{~cm}$ soil layers $\left(R^{2}=0.38\right.$, $P=0.019$; Fig. 3e; Table S2). Similar latitudinal patterns were observed for both vegetation and soil $C$ storage in all forests, although they were less pronounced (Fig. 3B and E). The same trends in the $C$ storage of vegetation and soil were observed at the $5^{\circ}$ latitudinal scale, and the $R^{2}$ values were even higher (Fig. $3 C$ and F; Table S2). Total forest $C$ storage for both all forests and mature forests had no apparent latitudinal patterns at the $2^{\circ}$ or $5^{\circ}$ latitudinal scales (Table S2).

\subsection{Allocation ratios of forest $C$ storage between vegetation and soil}

The allocation ratios of forest $C$ storage between vegetation and soil decreased significantly with increasing latitude (Fig. 4). In detail, the ratios between vegetation and $0-10 \mathrm{~cm}$ soil decreased logarithmically from 4.17 to $1.03\left(R^{2}=0.81, P<0.001\right.$, Fig. 4), while the ratios between vegetation and $0-100 \mathrm{~cm}$ soil decreased logarithmically from 1.55 to $0.31\left(R^{2}=0.78, P<0.001\right.$, Fig. 4).

\subsection{Controlling factors on the spatial distribution of forest $C$ storage}

SEM analysis showed that climate, soil nutrients, and soil environment can explain $66 \%$ of the spatial variation in vegetation $C$ storage, with climate contributing $60 \%$ and exerting a strong positive effect (Fig. 5A). Climate, soil environment, and SOM inputs explained $81 \%$ of the spatial variation in the $0-10 \mathrm{~cm}$ soil $\mathrm{C}$ storage. And again, climate was the most important factor, contributing $99 \%$ and exerting a negative impact on soil C storage (Fig. 5B). SEM identified no dominant controlling factor for total forest $\mathrm{C}$ storage (figures not shown).

Path analysis from the perspective of climate, soil nutrients, and soil texture, explained $85 \%$ of the variation in the allocation ratios between vegetation and $0-10 \mathrm{~cm}$ soil. The direct path coefficients of MAT and MAP were highest, at 0.56 and 0.50 , respectively (Fig. 6). Similarly, MAT and MAP were also the main factors controlling 


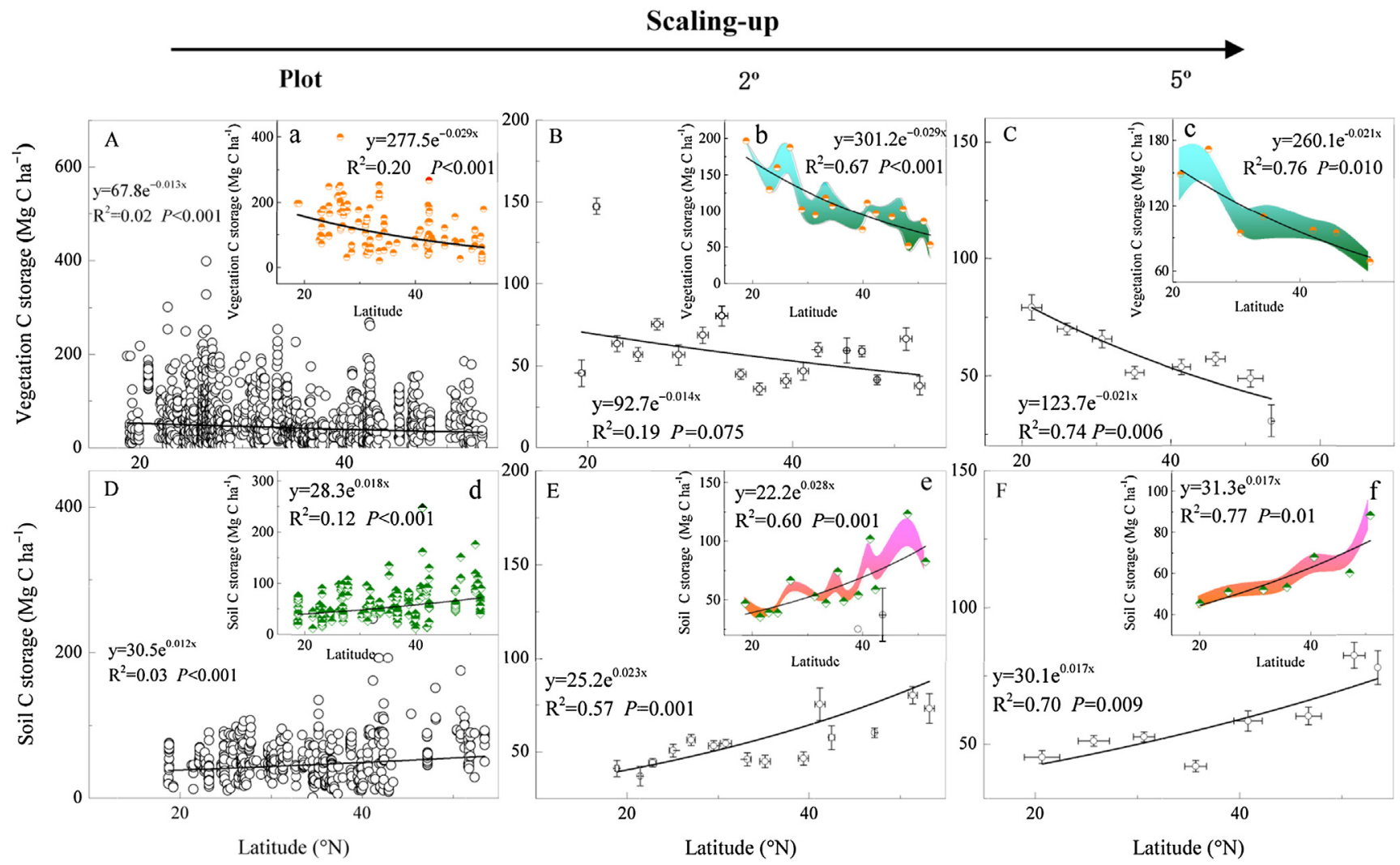

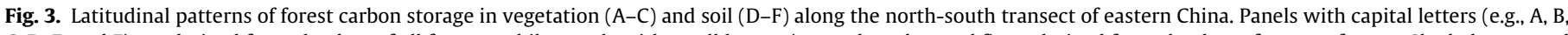

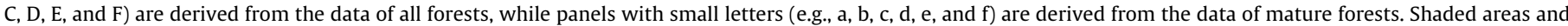
error bars represent standard error.

spatial variations in the allocation ratios of between vegetation and $0-100 \mathrm{~cm}$ soil (Table S3). Unexpectedly, no apparent relationships between forest $\mathrm{C}$ storage and elevation were observed (Figs. S3 and S4).

\subsection{Modeling forest $C$ storage in vegetation and soil}

Using the relationships between vegetation $C$ storage and MAT $\left(R^{2}=0.60\right.$; Fig. S5A $)$ or MAP $\left(R^{2}=0.66\right.$; Fig. S5B $)$, we established a model to estimate vegetation $C$ storage in forests at the $2^{\circ}$ latitudinal scale. The model was well validated $\left(R^{2}=0.80\right)$ using published data (Luo, 1996) (Fig. 7). Similarly, we established a model to estimate soil $C$ storage using the $0-10 \mathrm{~cm}$ soil $C$ storage and MAT $\left(R^{2}=0.826\right.$; Fig. S5C $)$ or MAP $\left(R^{2}=0.639\right.$; Fig. S5D $)$ data of mature

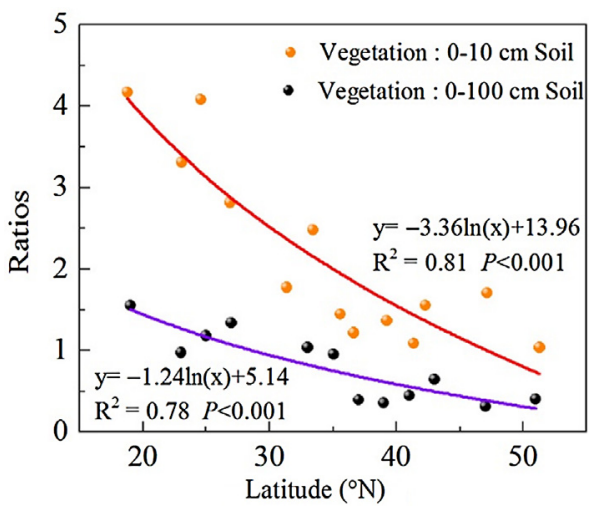

Fig. 4. Changes in the allocation ratios of forest carbon storage between vegetation and soil with latitude along the north-south transect of eastern China. forests at the $2^{\circ}$ latitudinal scale (Fig. 7). The data of all forests for soil $C$ storage may well validated the model $\left(R^{2}=0.78\right.$; Fig. 7$)$. Moreover, we validated the $2^{\circ}$ latitudinal scale models using the relationships between vegetation $C$ storage and MAT $\left(R^{2}=0.803\right.$; Fig. S6A) or MAP $\left(R^{2}=0.675\right.$; Fig. S6B), and between the $0-10 \mathrm{~cm}$ soil C storage and MAT $\left(R^{2}=0.773\right.$; Fig. S6C $)$ or MAP $\left(R^{2}=0.605\right.$; Fig. S6D) at the $5^{\circ}$ latitudinal scale. The models of vegetation and soil C storage were validated at the $5^{\circ}$ latitudinal scale $\left(R^{2}=0.77\right.$, RMSE $=18.77$ for vegetation $C$ storage $; R^{2}=0.89$, RMSE $=6.05$ for soil C storage).

The vegetation and soil $C$ storage models are described by Eqs. (2) and (3), respectively:

$V C=1721.097 \times \frac{0.05+\exp (0.000158 \times M A P)}{1+\exp (-0.037 \times(M A T-95.606))}+16.564$

$\mathrm{SC}=4.126 \times \exp (-0.378 \times M A T)-0.011 \times M A P+63.322$

where $V C$ is vegetation $C$ storage $\left(\mathrm{MgCha}^{-1}\right)$ and $S C$ is $0-10 \mathrm{~cm}$ soil $\mathrm{C}$ storage $\left(\mathrm{MgC} \mathrm{ha}^{-1}\right)$ at the $2^{\circ}$ latitudinal scale.

\section{Discussion}

\subsection{Latitudinal patterns in forest $C$ storage}

The variations in both vegetation (36.05-94.87 $\mathrm{MgCha}^{-1}$, with an average of $61.38 \mathrm{MgCha}^{-1}$; Fig. 2) and soil C storage $\left(\sim 123.46 \mathrm{MgCha}^{-1}\right.$ in the $0-100 \mathrm{~cm}$ soil layer) with increasing latitude were similar to the results of previous studies in different regions (Li et al., 2004; Xie et al., 2004; Zhou et al., 2000). Vegetation $\mathrm{C}$ storage in forests decreased with increasing latitude, especially for mature forests. However, soil C storage in forests 


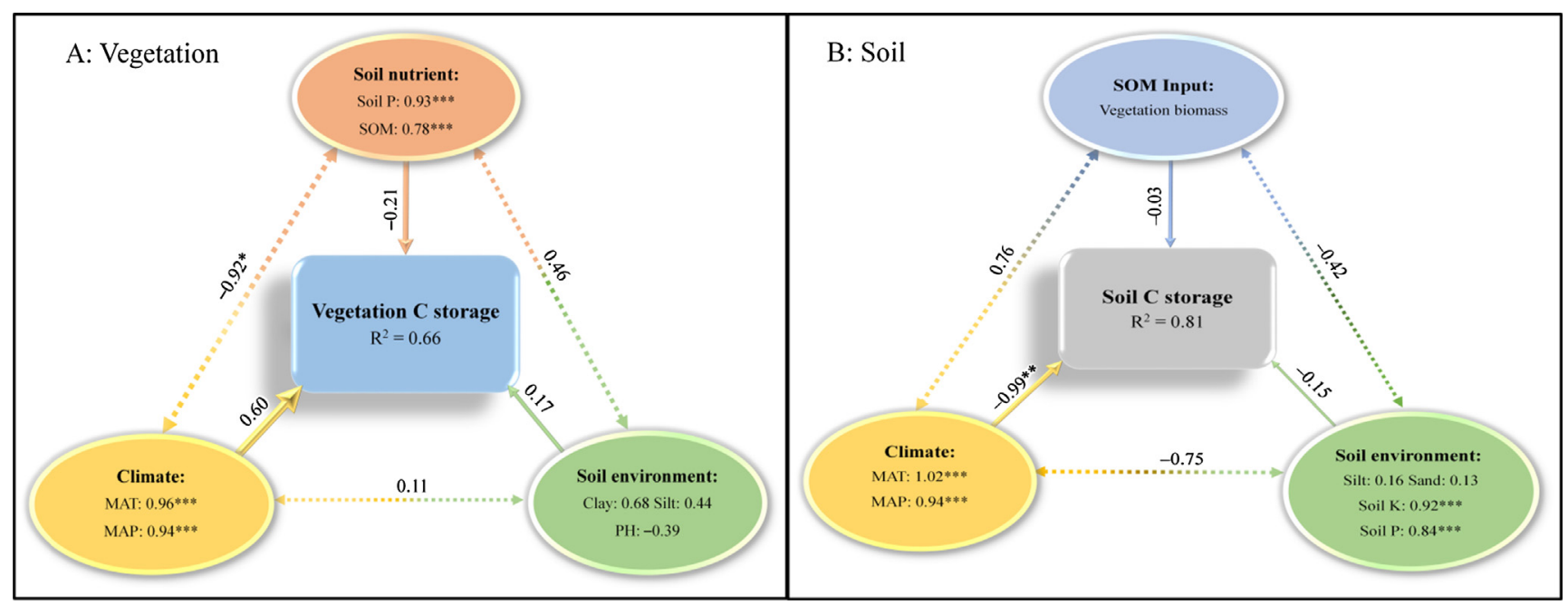

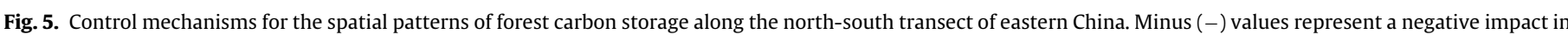

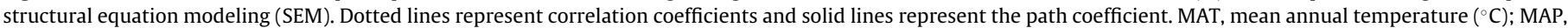

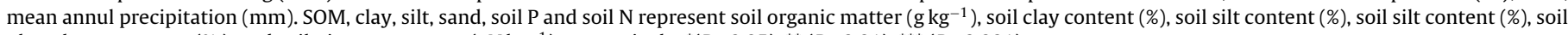
phosphorus content $(\%)$, and soil nitrogen storage $\left(\mathrm{t} \mathrm{N} \mathrm{ha}^{-1}\right)$, respectively. ${ }^{*}(P<0.05),{ }^{* *}(P<0.01),{ }^{* * *}(P<0.001)$.

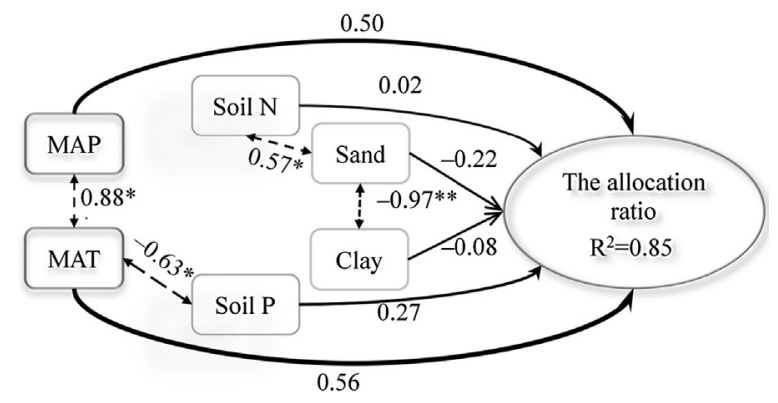

Fig. 6. Control mechanisms for the allocation ratios of forest carbon storage between vegetation and $0-10 \mathrm{~cm}$ soil. Minus $(-)$ values represent a negative impact in path analysis. Dotted lines represent correlation coefficients. Solid lines represent direct path coefficients. See Fig. 5 for the abbreviations of parameters. ${ }^{*}(P<0.05)$, ${ }^{* *}$ $(P<0.01)$.

increased significantly with increasing latitude, irrespective of forest age and soil depth, which is also similar to previous studies in different regions (Lal, 2005; Wang et al., 2001b). Our results verified the assumption that the latitudinal patterns were opposite for vegetation C storage (negative) and for soil (positive) C storage, and as a result there is no clear change in total forest $C$ storage (vegetation + soil). It is necessary to explain the stronger latitudinal patterns for vegetation $C$ storage in mature forests than those of all forests. As mentioned-above, the data used here were mainly collected from the published literatures. Therefore, the influence of randomly selected plots and variable forest ages is likely very strong for all forests, and such data may obscure spatial patterns because we cannot delete the effects of human disturbance. In contrast, when only mature forests were considered, the data should reflect the real spatial patterns in vegetation $C$ storage, which depended on climate at the large scale, because only low intensity or no apparent human disturbance occurred in these plots in recent decades.

The results of this study also emphasized the importance of scale selection in the analysis of forest C storage (Levin, 1992; Luo et al., 2001). The latitudinal patterns were dependent on the statistical scales, with spatial patterns in forest $C$ storage becoming stronger with increasing scale (i.e., from plot scale, to $2^{\circ}$ latitudinal scale, to $5^{\circ}$ latitudinal scale; Fig. 3 ). The most plausible explanation for these differences is that random sampling and forest age in the different climate regions may weaken latitudinal variations at the plot scale.

\subsection{Controlling mechanisms for the spatial patterns of forest $C$ storage}

Latitudinal patterns in vegetation $C$ storage were primarily controlled by climate factors, and increased with rising temperature and precipitation, which is consistent with past studies in different regions (Liu et al., 2014). By impacting on water demand, water balance, and vegetation photosynthesis, temperature and
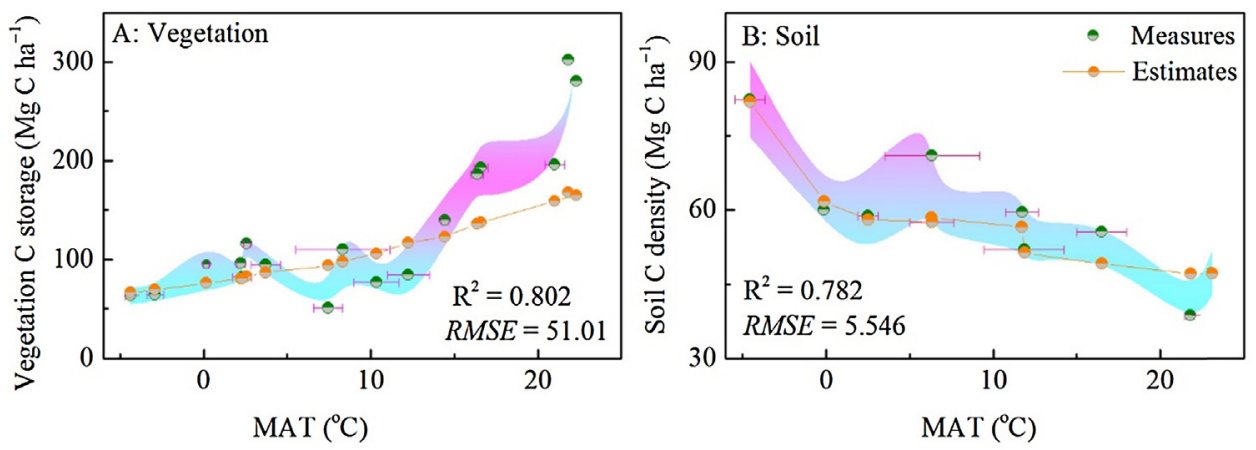

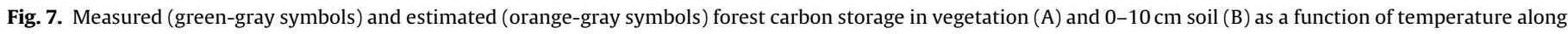
the north-south transect of eastern China. MAT, mean annual temperature $\left({ }^{\circ} \mathrm{C}\right)$; RMSE, root-mean-square error. Shaded areas and error bars represent standard error. 
precipitation affect net primary productivity as well as the horizontal distribution of vegetation (Davidson et al., 2000; Prentice and Fung, 1990). These relationships were reflected in the significant positive effects of temperature and precipitation on vegetation $\mathrm{C}$ storage along the NSTEC. These positive effects may plausibly be explained by increased levels of water availability and heat, which promoted higher vegetation productivity. However, a more complex view is that the long-term accumulation of SOC in forests depends on the balance between SOM input and decomposition. SOM input is contributed by litter and root secretion, which are commonly positively related to primary production in forests (interactively controlled by MAT and MAP in Chinese forests). In contrast, SOM decomposition is primarily controlled by temperature, increasing with increasing temperature under no serious limitation of soil moisture. Therefore, temperature and precipitation exerted a negative effect on soil $\mathrm{C}$ storage along the NSTEC (Stegen et al., 2011). Possible explanations for the negative effect are as follow: (1) higher water availability and heat promoted higher vegetation productivity, or, in other words, enhanced SOM inputs; and (2) higher temperatures and precipitation had a strong positive effect that accelerated SOM decomposition (Conant et al., 2011; Giardina and Ryan, 2000; James, 2001; Luo et al., 2010), which may be reflected in the exponential functions between SOM decomposition rate and temperature (Conant et al., 2011; Davidson et al., 2000; Vitousek, 1994). In short, soil C storage ultimately reflects the stronger effect of temperature on SOM decomposition along the NSTEC, such that soil C storage increases with increasing latitude.

\subsection{Climate controls on the allocation ratios of forest $C$ storage between vegetation and soil}

The allocation ratios of forest $C$ storage between vegetation and soil decreased with increasing latitude along the NSTEC, irrespective of soil depth, reflected by the opposing latitudinal patterns between vegetation $C$ storage and soil $C$ storage. Our findings demonstrated that climate (e.g., MAT and MAP) controlled the spatial variations in the allocation ratios of vegetation to soil. Climate plays an important role in vegetation productivity and SOM inputs to soil, but it also exerts a stronger influence on SOM decomposition at a large scale (as discussed above). For example, MAT and MAP at low latitude were relatively higher than at high latitude, and hence in the south the growth rates of vegetation were enhanced and SOM decomposition rates were synchronously stronger (Davidson et al., 2000; Liu et al., 2012). Conversely, at high latitudes, lower MAT and MAP depressed vegetation productivity and SOM input to the soil, but more importantly restricted SOM decomposition, resulting in an apparent accumulation of SOM (Post et al., 1982).

In summary, our findings provided new insights into the spatial patterns of vegetation and soil $\mathrm{C}$ storage in forests. These findings allow us to more accurately predict forest $C$ storage and, as a result, allow for more effective implementation of reforestation to partially offset anthropogenic $\mathrm{CO}_{2}$ emissions.

\section{Acknowledgements}

We appreciated the data share from National Data Sharing Infrastructure of Earth System Science (http://www.geodata.cn/). This work was funded by National Natural Science Foundation of China (31470506, 31290201), the Chinese Academy of Sciences Strategic Priority Research Program (XDA05050702), and the Program for Kezhen Distinguished Talents in Institute of Geographic Sciences and Natural Resources Research (2013RC102). Data share may contact with He N.P. (henp@igsnrr.ac.cn).

\section{Appendix A. Supplementary data}

Supplementary data associated with this article can be found, in the online version, at http://dx.doi.org/10.1016/j.ecolind.2015. 10.054 .

\section{References}

Bakken, T.H., Aase, A.G., Hagen, D., Sundt, H., Barton, D.N., Lujala, P., 2014. Demonstrating a new framework for the comparison of environmental impacts from small- and large-scale hydropower and wind power projects. J. Environ. Manage. 140, 93-101.

Barto, E.K., Alt, F., Oelmann, Y., Wilcke, W., Rillig, M.C., 2010. Contributions of biotic and abiotic factors to soil aggregation across a land use gradient. Soil Biol. Biochem. 42, 2316-2324.

Bonan, G.B., 2008. Forests and climate change: forcings, feedbacks, and the climate benefits of forests. Science 320, 1444-1449.

Chai, H., Yu, G.R., He, N.P., Wen, D., Li, J., Fang, J.P., 2015. Vertical distribution of soil carbon, nitrogen, and phosphorus in typical Chinese terrestrial ecosystems. Chin. Geogr. Sci. 25, 549-560.

Cheng, L.A., Mendonca, G., de Farias, J.C., 2014. Physical activity in adolescents: analysis of the social influence of parents and friends. J. Pediatria 90, 35-41.

Conant, R.T., Ryan, M.G., Agren, G.I., Birge, H.E., Davidson, E.A., Eliasson, P.E., Evans, S.E., Frey, S.D., Giardina, C.P., Hopkins, F.M., Hyvonen, R., Kirschbaum, M.U.F., Lavallee, J.M., Leifeld, J., Parton, W.J., Steinweg, J.M., Wallenstein, M.D., Wetterstedt, J.A.M., Bradford, M.A., 2011. Temperature and soil organic matter decomposition rates - synthesis of current knowledge and a way forward. Global Change Biol. 17, 3392-3404.

Cook, R.L., Binkley, D., Mendes, J.C.T., Stape, J.L., 2014. Soil carbon stocks and forest biomass following conversion of pasture to broadleaf and conifer plantations in southeastern Brazil. Forest Ecol. Manage. 324, 37-45.

Couto, T., Duarte, B., Cacador, I., Baeta, A., Marques, J.C., 2013. Salt marsh plants carbon storage in a temperate Atlantic estuary illustrated by a stable isotopic analysis based approach. Ecol. Indic. 32, 305-311.

Davidson, E.A., Janssens, I.A., 2006. Temperature sensitivity of soil carbon decomposition and feedbacks to climate change. Nature 440, 165-173.

Davidson, E.A., Trumbore, S.E., Amundson, R., 2000. Biogeochemistry - soil warming and organic carbon content. Nature 408, 789-790.

Dixon, R.K., Solomon, A.M., Brown, S., Houghton, R.A., Trexier, M.C., Wisniewski, J., 1994. Carbon pools and flux of global forest ecosystems. Science 263 $185-190$.

Fan, S., Gloor, M., Mahlman, J., Pacala, S., Sarmiento, J., Takahashi, T., Tans, P., 1998 A large terrestrial carbon sink in North America implied by atmospheric and oceanic carbon dioxide data and models. Science 282, 442-446.

Fang, J.Y., Guo, Z.D., Piao, S.L., Chen, A.P., 2007. Terrestrial vegetation carbon sinks in China, 1981-2000. Sci. China: Earth Sci. 50, 1341-1350.

Fang, J.Y., Zhao, K., Liu, S.H., 1998. Factors affecting soil respiration in reference with temperature's role in the global scale. Chin. Geogr. Sci. 8, 246-255.

Fu, B.J., Liu, G.H., Chen, L.D., Ma, K.M., Li, J.R., 2001. Scheme of ecological regionalization in China. Acta Ecol. Sin. 21, 1-6.

Gao, Y.Z., He, H.L., Zhang, L., Lu, Q.Q., Yu, G.R., Zhang, Z.L., 2013. Spatio-temporal variation characteristics of surface net radiation in China over the past 50 years. J. Geo-Inform. Sci. 15, 1-10.

Giardina, C.P., Ryan, M.G., 2000. Evidence that decomposition rates of organic carbon in mineral soil do not vary with temperature. Nature 404, 858-861.

Gower, S.T., 2003. Patterns and mechanisms of the forest carbon cycle. Annu. Rev Environ. Resour. 28, 169-204.

Gustafsson, J.E., Martenson, R., 2002. Structural equation modeling with AMOS: basic concepts, applications, and programming. In: Contemporary Psychology-Apa Review of Books., pp. 478-480.

He, J.S., 2012. Carbon cycling of Chinese forests: from carbon storage, dynamics to models. Sci. Sin. Vitae 42, 252-254.

Herrero, C., Bravo, F., 2012. Can we get an operational indicator of forest carbon sequestration? A case study from two forest regions in Spain. Ecol. Indic. 17, $120-126$.

Houghton, R.A., 2005. Aboveground forest biomass and the global carbon balance. Global Change Biol. 11, 945-958.

James, J.M., 2001. Climate Change 2001: Impacts, Adaptation and Vulnerability. Cambridge University Press, Cambridge, pp. 31-36.

Jarvis, P.G., 1989. Atmospheric carbon-cioxide and forests. Philos. Trans. R. Soc. B 324, 369-392.

Jelinski, D.E., Wu, J.G., 1996. The modifiable areal unit problem and implications for landscape ecology. Landsc. Ecol. 11, 129-140.

Kato, T., Tang, Y.H., 2008. Spatial variability and major controlling factors of $\mathrm{CO}_{2}$ sink strength in Asian terrestrial ecosystems: evidence from eddy covariance data. Global Change Biol. 14, 2333-2348.

Kerr, S., Liu, S.G., Pfaff, A.S.P., Hughes, R.F., 2003. Carbon dynamics and land-use choices: building a regional-scale multidisciplinary model. J. Environ. Manage. $69,25-37$.

Lal, R., 2005. Forest soils and carbon sequestration. Forest Ecol. Manage. 220, $242-258$

Levin, S.A., 1992. The problem of pattern and scale in ecology. Ecology 73 , 1943-1967. 
Li, K.R., Wang, S.Q., Cao, M.K., 2004. Vegetation and soil carbon storage in China. Sci. China: Earth Sci. 47, 49-57.

Liu, G.H., Fu, B.J., Fang, J.Y., 2000. Carbon dynamics of Chinese forests and its contribution to global carbon balance. Acta Ecol. Sin. 20, 733-740.

Liu, J., Buheaosier, Y., 2000. Study on spatial-temporal feature of modern land-use change in China: using remote sensing techniques. Quat. Sci. 20, 229-239.

Liu, Y.C., Yu, G.R., Wang, Q.F., Zhang, Y.J., 2012. Huge carbon sequestration potential in global forests. J. Resour. Ecol. 3, 193-201.

Liu, Y.C., Yu, G.R., Wang, Q.F., Zhang, Y.J., 2014. How temperature, precipitation and stand age control the biomass carbon density of global mature forests. Global Ecol. Biogeogr. 23, 323-333.

Lu, N., Sun, G., Feng, X.M., Fu, B.J., 2013. Water yield responses to climate change and variability across the North-South Transect of Eastern China (NSTEC). J. Hydrol. 481, 96-105.

Luo, C.Y., Xu, G.P., Chao, Z.G., Wang, S.P., Lin, X.W., Hu, Y.G., Zhang, Z.H., Duan, J.C., Chang, X.F., Su, A.L., Li, Y.N., Zhao, X.Q., Du, M.Y., Tang, Y.H., Kimball, B., 2010. Effect of warming and grazing on litter mass loss and temperature sensitivity of litter and dung mass loss on the Tibetan plateau. Global Change Biol. 16, 1606-1617.

Luo, T.X., (Doctor of Philosophy) 1996. Patterns of Net Primary Productivity for Chinese Major Forest Types and their Mathematical Models. Chinese Academy of Sciences.

Luo, Y.Q., Wan, S.Q., Hui, D.F., Wallace, L.L., 2001. Acclimatization of soil respiration to warming in a tall grass prairie. Nature 413, 622-625.

Miao, Q., Shi, X., Yu, D., Wang, H., Ren, H., Sun, W., Zhao, Y., 2010. Scale effect of climatic factors on forest organic carbon. Acta Pedolog. Sin. 47, 271-278.

Mitchell, R.J., 1992. Testing evolutionary and ecological hypotheses using pathanalysis and structural equation modeling. Funct. Ecol. 6, 123-129.

Odum, E., 1969. The strategy of ecosystem development. Science 164, 262-270.

Parton, W.J., Scurlock, J.M.O., Ojima, D.S., Gilmanov, T.G., Scholes, R.J., Schimel, D.S. Kirchner, T., Menaut, J.C., Seastedt, T., Moya, E.G., Kamnalrut, A., Kinyamario, J.I. 1993. Observations and modeling of biomass and soil organic matter dynamics for the grassland biome worldwide. Global Biogeochem. Cycles 7, 785-809.

Petraitis, P.S., Dunham, A.E., Niewiarowski, P.H., 1996. Inferring multiple causality: the limitations of path analysis. Funct. Ecol. 10, 421-431.

Post, W.M., Emanuel, W.R., Zinke, P.J., Stangenberger, A.G., 1982. Soil carbon pools and world life zones. Nature 298, 156-159.

Prentice, K.C., Fung, I.Y., 1990. The sensitivity of terrestrial carbon storage to climate change. Nature 346, 48-51.

Rastetter, E.B., King, A.W., Cosby, B.J., Hornberger, G.M., Oneill, R.V., Hobbie, J.E., 1992. Aggregating fine-scale ecological knowledge to model coarser-scale attributes of ecosystems. Ecol. Appl. 2, 55-70.

Sackett, T.E., Smith, S.M., Basiliko, N., 2013. Indirect and direct effects of exotic earthworms on soil nutrient and carbon pools in North American temperate forests. Soil Biol. Biochem. 57, 459-467.

Sheng, W.P., Ren, S.J., Yu, G.R., Fang, H.J., Jiang, C.M., Zhang, M., 2011. Patterns and driving factors of WUE and NUE in natural forest ecosystems along the NorthSouth Transect of Eastern China. J. Geogr. Sci. 21, 651-665.

Sollins, P., Homann, P., Caldwell, B.A., 1996. Stabilization and destabilization of soil organic matter: Mechanisms and controls. Geoderma 74, 65-105.
Stegen, J.C., Swenson, N.G., Enquist, B.J., White, E.P., Phillips, O.L., Jorgensen, P.M., Weiser, M.D., Mendoza, A.M., Vargas, P.N., 2011. Variation in above-ground forest biomass across broad climatic gradients. Global Ecol. Biogeogr. 20, 744-754

Van Der Werf, G.R., Randerson, JT., Collatz, G.J., Giglio, L., 2003. Carbon emissions from fires in tropical and subtropical ecosystems. Global Change Biol. 9, 547-562.

Vitousek, P.M., 1994. Beyond global warming - ecology and global change. Ecology 75, 1861-1876.

Wang, R.L., Yu, G.R., He, N.P., Wang, Q.F., Zhao, N., Xu, Z.W., Ge, J.P., 2015. Latitudinal variation of leaf stomatal traits from species to community level in forests: linkage with ecosystem productivity. Sci. Rep. 5, 14454, http://dx.doi.org/10.1038/ srep 14454.

Wang, S.Q., Zhou, C.H., Li, K.R., Zhou, S.L., Huang, F.H., 2000. Analysis on spatial distribution characteristics of soil organic carbon reservoir in China. Acta Geograph. Sin. 55, 533-544.

Wang, S.Q., Zhou, C.H., Li, K.R., Zhu, S.L., 2001a. Estimation of soil organic carbon reservoir in China. J. Geogr. Sci. 11, 3-13.

Wang, X.K., Feng, Z.W., Ouyang, Z.Y., 2001b. Vegetation carbon storage and density of forest ecosystems in China. Chin. J. Appl. Ecol. 12, 13-16.

Warring, R.H., Running, S.W., 2007. Forest Ecosystems: Analysis at Multiple Scales. Elsevier Academic Press, pp. 347-408.

Wei, Y.W., Yu, D.P., Wang, Q.J., Zhou, L., Zhou, W.M., Fang, X.M., Gu, X.P., Dai, L.M. 2013. Soil organic carbon density and its influencing factors of major forest types in the forest region of Northeast China. Chin. J. Appl. Ecol. 24, 3333-3340.

Wiens, J.A., 1989. Spatial scaling in ecology. Funct. Ecol. 3, 385-397.

Wim, d.V., 2014. Forest ecology nutrients trigger carbon storage. Nat. Climate Change 4, 425-426.

Wu, J., Jelinski, D.E., Luck, M., Tueller, P.T., 2000. Multiscale analysis of landscape heterogeneity: scale variance and pattern metrics. Geograp. Inform. Sci. 6, 6-19.

Wu, J.G., Li, H.B., 2006. Concepts of scale and scaling. In: Scaling and Uncertainty Analysis in Ecology: Methods and Applications., pp. 3-15.

Xie, X.L., Sun, B., Zhou, H.Z., Li, Z.P., 2004. Soil carbon stocks and their influencing factors under native vegetations in China. Acta Pedolog. Sin. 41, 687-699.

Xu, L., He, N.P., Yu, G.R., Wen, D., Gao, Y., He, H.L., 2015. Pedotransfer functions of bulk density lead to high uncertainty in soil organic carbon estimation at regional scales: evidence from Chinese terrestrial ecosystems. J. Geophys. Res. 120, http://dx.doi.org/10.1002/2015JG002929.

Xu, Y., Jiang, M., 2015. Forest carbon pool characteristics and advances in the researches of carbon storage and related factors. Acta Ecol. Sin. 35, 926-933.

Yu, D.P., Wang, X.Y., Yin, Y., Zhan, J.Y., Lewis, B.J., Tian, J., Bao, Y., Zhou, W.M., Zhou, L., Dai, L.M., 2014. Estimates of forest biomass carbon storage in Liaoning Province of Northeast China: a review and assessment. PLoS ONE 9, http://dx.doi.org/10. 1371/journal.pone.0089572.

Zhang, X.S., Yang, D.A., 1995. Allocation and study on global change transects in China. Quat. Sci. 15, 43-52.

Zhou, G.S., Wang, Y.H., Jiang, Y.L., Yang, Z.Y., 2002. Estimating biomass and net primary production from forest inventory data: a case study of China's Larix forests. Forest Ecol. Manage. 169, 149-157.

Zhou, Y.R., Yu, Z.L., Zhao, S.D., 2000. Carbon storage and budget of major Chinese forest types. Acta Phytoecol. Sin. 24, 518-522. 